\title{
Molecular targets in aortic aneurysm for establishing novel management paradigms
}

\author{
Chengkai Hu ${ }^{1,2}$, Kai Zhu ${ }^{1,2}$, Jun $\mathrm{Li}^{1,2}$, Chunsheng Wang ${ }^{1,2}$, Lao Lai ${ }^{1,2}$ \\ ${ }^{1}$ Department of Cardiac Surgery, Zhongshan Hospital, Fudan University, Shanghai 200032, China; ${ }^{2}$ Shanghai Institute of Cardiovascular Disease, \\ Shanghai 200032, China \\ Contributions: (I) Conception and design: H Lai, K Zhu, C Wang; (II) Administrative support: C Wang; (III) Provision of study materials or patients: \\ All authors; (IV) Collection and assembly of data: All authors; (V) Data analysis and interpretation: All authors; (VI) Manuscript writing: All authors; \\ (VII) Final approval of manuscript: All authors. \\ Correspondence to: Hao Lai. Department of Cardiac Surgery, Zhongshan Hospital, Fudan University, Shanghai 200032, China. \\ Email: lai.hao@zs-hospital.sh.cn; Chunsheng Wang. Department of Cardiac Surgery, Zhongshan Hospital, Fudan University, Shanghai 200032, \\ China. Email: wang.chunsheng@zs-hospital.sh.cn; Kai Zhu. Department of Cardiac Surgery, Zhongshan Hospital, Fudan University, Shanghai \\ 200032, China. Email: zhu.kai1@zs-hospital.sh.cn.
}

\begin{abstract}
Aortic aneurysm (AA) is a lethal disease and presents a large challenge for surgeons in the clinic. Although surgical management remains the major choice of AA, operative mortality remains high. With advances in understanding of the mechanisms of AAs, molecular targets, such as matrix metalloproteinases (MMPs), D-dimer, and inflammation markers, including C-reactive protein, interleukins and phagocytes, are important in the pathology of development of AA. These markers may become important for improving the diagnostic quality and provide more therapeutic choices for treatment of AA. Although these new markers require long-term trials before they can be translated into the clinic, they can still be helpful in determining new directions. The main aim of this review is to discuss the current findings of molecular targets in progression of AA and discuss the potential application of these new targets for managing this disease.
\end{abstract}

Keywords: Aortic aneurysm (AA); molecular targets; inflammation; remodeling; nanomedicine

Submitted Feb 28, 2017. Accepted for publication Oct 10, 2017.

doi: $10.21037 /$ jtd.2017.10.63

View this article at: http://dx.doi.org/10.21037/jtd.2017.10.63

\section{Introduction}

Aortic aneurysm (AA) is a potential lethal disease with an increasing incidence rate that reaches approximately $10.4 / 100,000$ people each year $(1,2)$. The general feature of AA is a lack of obvious evidence or clinical symptoms for determining its presence (3), and death due to ruptured AA is common $(4,5)$. Progression of AA leads to unpredictable features of this disease and can lead to unexpected rupture. The annual incidence of aortic dissection and rupture is 3.5/100,000 patients (6). The various histological, anatomical, and clinical presentations need to be carefully considered before deciding on treatment options for AA. Surgical repair of AA is the main treatment with a mean 30 -day mortality rate of $8.2 \%$ (95\% confidence interval:
6.4-10.6) (7). In the clinic, physicians usually use medicine to delay the progression of AA, such as traditional betaadrenergic receptor blockers, when AA does not reach the standard for surgery. Recently, molecular targets of development of AA have been found with technological innovations. These targets include matrix metalloproteinases (MMPs), elastin-peptides (SEP), C-reactive protein, and PIIINP-collagen, which have provided a new direction for diagnosis and management of AA.

\section{Pathophysiology of AA}

The aorta is a heterogeneous vessel with different components in thoracic aortic aneurysm (TAA) and abdominal aortic aneurysm (AAA), as reported in 


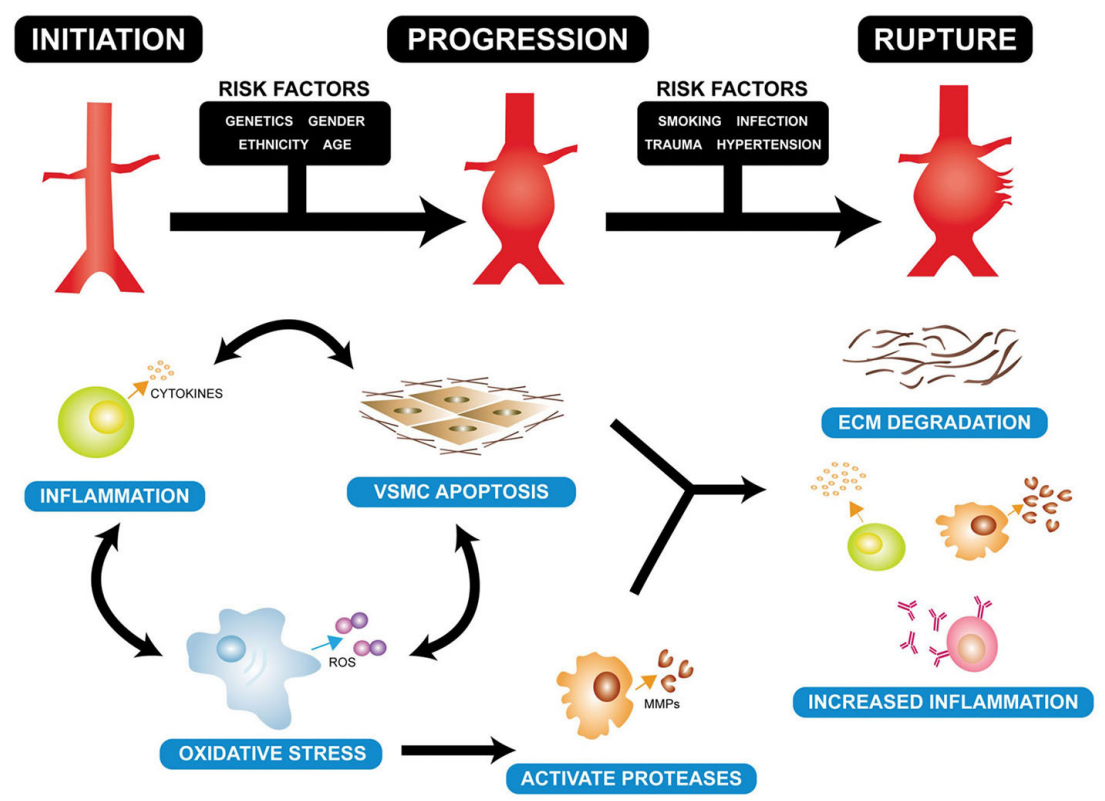

Figure 1 Schema showing the inflammation process in AA (10). AA, aortic aneurysm.

previous reviews $(8,9)$. However, matrix remodeling and inflammation are similar between TAA and AAA. Formation of the AA is correlated with inflammatory infiltrates in apoptosis of vascular smooth muscle cells and extracellular matrix degradation (Figure 1) (10). Additionally, a change in matrix proteins and a variety of transforming growth factor (TGF) $-\beta$ signals appear to be vital for development of TAA $(9,11,12)$. The weaken of the aortic ultrastructure and increased the risk of dilatation, dissection, and rupture may be caused by this alteration $(13,14)$. TGF- $\beta$ can affect matrix degradation by regulating alternate pathways, especially in Marfan syndrome. A previous study showed that in patients with TAA, the TGF- $\beta 2$ signal is decreased through cells expressing TGF- $\beta$ RIIb and mutations in this receptor result in an increase in TGF- $\beta 2$ signal (15). This suggests that an increase in TGF- $\beta$ signal may lead to development of aortic pathogenesis. The TGF- $\beta 2$ signal finding has aroused a wide concern in the intracellular signaling pathway $(16,17)$. Moreover, pro-inflammatory chemokines and cytokines expedite the inflammatory process. MMPs, which are a large family of enzymes, are derived from smooth muscle cell production and response to cyclic strain that can also progress degradation of the extracellular matrix (18). The function of increased MMP levels in the progression of AAs is important $(19,20)$. In certain cases, an imbalance in medial expression of MMPs, specifically the gelatinases (MMP-2 and MMP-9) and tissue inhibitors of metalloproteinases (TIMP-2 and TIMP-1), result in accelerated proteolytic degradation of elastin and collagen fibers $(21,22)$. They have found that MMP-9 levels were increased in TAA (Figure 2) compared with controls and the levels of MMP-2 was no obviously change in TAA compared with controls (Figure 3). Additionally, TIMP-1 and TIMP-2 levels were significantly lower in TAA compared with controls (Figure 4). All studies showed that the ratio of MMP-9 to TIMP-1 was 3.7 times in TAA compared with controls. The ratio of MMP-9 to TIMP-2 in TAA was 26.5 times that of controls. Notably, MMP-2 and -9 have elastolytic and collagenolytic properties (23). Elastolytic and collagenolytic properties can increase stiffness of the thoracic aortic wall and decrease elastic ability, which lead to the appearance of AA. Therefore, inflammation, matrix degradation and remodeling weaken aortic tensile strength and lead to formation of AA.

\section{Current parameters in the diagnosis of AA}

Although AA usually develops asymptomatically, once a certain size is reached, the risk of dissection, rupture, and death could be sharply increases. Due to the asymptomatic nature, many patients with AA would not be diagnosed until complications occur. Therefore, there are many parameters that are used to help diagnosis and management of complications. 
MMP-9 in TAA compared to control

\begin{tabular}{|c|c|c|c|c|c|c|c|c|c|}
\hline \multirow[t]{2}{*}{ Study name } & \multicolumn{4}{|c|}{ Statistics for each study } & \multicolumn{3}{|c|}{ Std diff in means and $95 \% \mathrm{Cl}$} & \multirow[b]{2}{*}{$\begin{array}{l}\text { Relative } \\
\text { weight }\end{array}$} & \multirow[b]{2}{*}{$\begin{array}{l}\text { Relative } \\
\text { weight }\end{array}$} \\
\hline & $\begin{array}{l}\text { Std diff in } \\
\text { means }\end{array}$ & $\begin{array}{l}\text { Standard } \\
\text { error }\end{array}$ & $Z$ value & $P$ value & & & & & \\
\hline Schmoker et al. 2007 [19] & 9] 0.374 & 0.275 & 1.359 & 0.174 & & D & & 78.99 & \\
\hline Koullias et al. 2004 [22] & 7.508 & 0.968 & 7.752 & 0.000 & & & 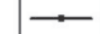 & 6.36 & \\
\hline \multirow[t]{3}{*}{ Mi et al. 2011 [24] } & 1.322 & 0.638 & 2.071 & 0.038 & & $\rightarrow$ & & 14.65 & \\
\hline & 0.966 & 0.244 & 3.956 & 0.000 & & 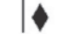 & & & \\
\hline & & & & & $.00-5.00$ & 0.00 & 5.001 & .00 & \\
\hline
\end{tabular}

Control TAA

Figure 2 MMP-9 levels are increased in TAA compared with controls (21). TAA, thoracic aortic aneurysm.

MMP-2 in TAA compared to control

\begin{tabular}{|c|c|c|c|c|c|c|c|c|c|}
\hline \multirow[t]{2}{*}{ Study name } & \multicolumn{4}{|c|}{ Statistics for each study } & \multicolumn{5}{|c|}{ Std diff in means and $95 \% \mathrm{Cl}$} \\
\hline & $\begin{array}{l}\text { Std diff in } \\
\text { means }\end{array}$ & $\begin{array}{l}\text { Standard } \\
\text { error }\end{array}$ & $Z$ value $F$ & $P$ value & & & & & \\
\hline Schmoker et al. 2007 [19] & -0.907 & 0.283 & -3.211 & 0.001 & & & & & \\
\hline Koullias et al. 2004 [22] & -0.424 & 0.423 & -1.003 & 0.316 & & & & & \\
\hline \multirow[t]{3}{*}{ Mi et al. 2011 [24] } & 1.551 & 0.705 & 2.201 & 0.028 & & & & & \\
\hline & -0.090 & 0.587 & -0.154 & 0.878 & & & & & \\
\hline & & & & & -4.00 & -2.00 & 0.00 & 2.00 & 4.00 \\
\hline$Q=10.57, P=0.005 ; I^{2}=81$ & $.1, \mathrm{Tau}^{2}=0.81$ & & & & & Contrc & l & TAA & \\
\hline
\end{tabular}

Figure 3 MMP-2 levels are not significantly different between TAA and controls (21). MMP, matrix metalloproteinase; TAA, thoracic aortic aneurysm.

TIMP-1 in TAA compared to control

\begin{tabular}{cccccccc} 
Study name & \multicolumn{5}{c}{ Statistics for each study } & Std diff in means and 95\% Cl & Relative \\
weight & Relative \\
weight \\
means
\end{tabular}

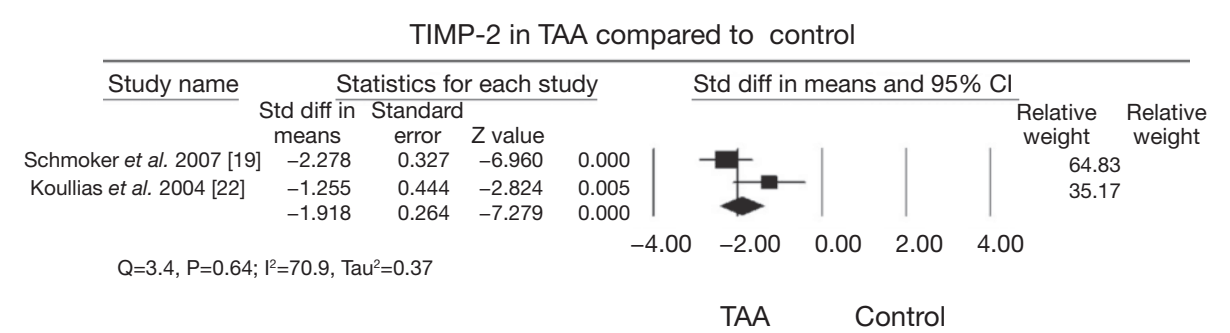

Figure 4 TIMP-1 and TIMP-2 are significantly decreased in TAA compared with controls (21). TIMP, tissue inhibitors of metalloproteinase; TAA, thoracic aortic aneurysm. 


\section{Size}

Size is one of the important characteristics in AA. However, AA grows in a generally indolent manner, increasing by approximately $1 \mathrm{~mm}$ each year (24). Interestingly, aneurysms with larger diameters incline to expand more rapidly. The annual growth rate with a $4.0 \mathrm{~cm}$ of ascending TAA is $0.10 \mathrm{~cm}$, while the annual growth rate with an $8.0 \mathrm{~cm}$ of ascending TAA is $0.19 \mathrm{~cm}$ (25). In AAA, ruptures appear in $25-41 \%$ of AAAs with a diameter $>50 \mathrm{~mm}$ over 5 years (26). In TAA, large aneurysms, especially the size greater than 5 to $6 \mathrm{~cm}$, expand more rapidly compared with small aneurysms (27-32). Therefore, the size of the AA is a good predictor for aortic rupture.

\section{Genes}

The AA is divided into atherosclerotic, syphilitic, bacterial, traumatic and congenital aneurysms, and dissecting aneurysms in the etiology. In the congenital aneurysms, the family factor is a major risk factor in the AA appearance and growth, the rate of diagnosed AA was lower in patients without family history than ones with first-degree relatives have diagnosed AA $(33,34)$. The congenital AA forms are associated with Marfan syndrome, Loeys-Dietz syndrome and Ehlers-Danlos syndrome and relevant genes contains FBN1, ACTA2, PRKG1, TGFBR1, TGFBR2 genes. The mutation of this genes can benefit to the AA appearance and progression. For example, the Marfan syndrome has associated with the mutation of FBN1 and the TGF- $\beta$ activation signal moreover the different position mutation of FBN1 has the different mechanism in the pathogenesis (35). The family genetic examination may have an application prospect to screen AA in individuals who have the family history using PCR amplification. But detection rate for genes mutations in familial AA is $<20 \%$ and many individuals with family history of AA have normal diameter of aortic. Thus, the effectively way to screen family AA is ultrasounds. In current, there is article suggested the standard of screen family AA is the age of screen first-degree relatives is 50 for male and 55 for female rather than the less than 60 (36-38).

\section{Mechanical sections}

Calculations of the mechanical sections of AA can be performed using six independent variables: aortic pressure, aortic diameter, and thickness of the aorta in systole and diastole. When the size of the aneurysm attached a key point, the aorta cannot continue to stretch in systole, which could increase the stress to the aortic wall (39). Magnetic resonance imaging (MRI) has been reported to be used in measuring the mechanical sections of AA. In one study of AAA, wall stress in the control group was lower than that the AA group by using a three-dimensionally reconstructed model (40). Therefore, these measurements can be predictive factors for indicating a higher risk of rupture of regions of AAs $(41,42)$.

\section{Biomarkers for $A A$}

Most patients with AA are asymptomatic until rupture of the aneurysm. Therefore, biomarkers, especially plasma proteins, might be useful for diagnosing and monitoring of AA in an early phase. Some circulating biomarkers have been established for AAA (43-45). Recent studies have shown that SEP can be used as a biomarker for predicting expansion of AAA (46-48). Additionally, matrix protease, interleukin-6, C-reactive protein, TNF- $\alpha, \mathrm{D}$-dimer, and IFN- $\gamma$ have also been studied by many research groups (49-54). Although there have been positive results regarding to these biomarkers in many studies, the numbers of the patients in trials are limited. Therefore, many difficulties need to be resolved before their translation into the clinic.

\section{Molecular targets in AA}

In progression of $\mathrm{AA}$, the quantity of production, such as MMP and matrix proteins, related to AA appears to change. These factors may become molecular targets for diagnosis and management of AA. Molecular target therapy has become a potential useful plan to treat AA.

\section{Inflammation targets}

Inflammation is a major component in progression of AA. Endothelial activation, recruitment of leukocytes and the up-regulation of adhesion molecules are important events in the early pathology of AA. Moreover, pro-inflammatory chemokines and cytokines can accelerate the inflammatory process of AA $(55,56)$. Therefore, inflammatory activities can become targets for the diagnosis and management of AA.

\section{Metabolism activities}

There is a general agreement that AAA formation has a close relationship with destruction of elastin and collagen 

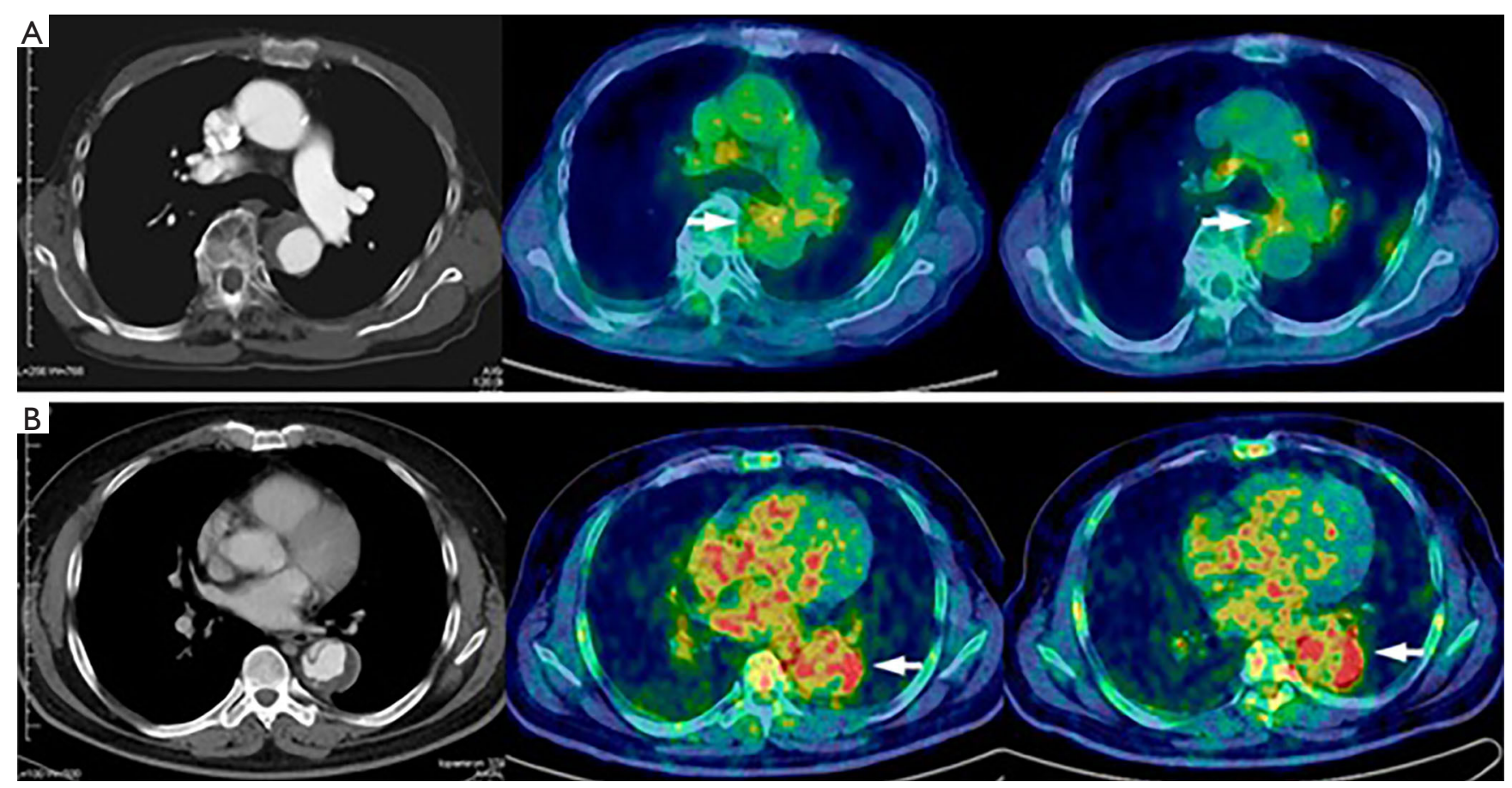

Figure $5{ }^{18} \mathrm{~F}$-FDG uptake to predict short and mid-term prognosis in medically controlled patients with AA dissection by comparing uptake of ${ }^{18} \mathrm{~F}$-FDG in controls and in patients with AAD. (A) ${ }^{18} \mathrm{~F}$-FDG SUV $\max$ and $\mathrm{SUV}_{\text {mean }}$ were on 50-minute images (middle) and 100-minute images (right) on patients with favorable outcome; (B) ${ }^{18} \mathrm{~F}-\mathrm{FDG} S \mathrm{SU}_{\max }$ and $\mathrm{SUV}_{\text {mean }}$ were on 50-minute images (middle) and on 100-minute images (right) on patients with unfavorable outcome (68). F-FDG, F-fluorodeoxy glucose; SUV, standardized uptake value; AA, aortic aneurysm; AAD, acute aortic dissection.

at the medial level. Additionally, metabolism of elastin and collagen appear to be related to dispensability of AA (57). Several European studies have shown that the increased metabolic activity is associated with formation of AA, which can be used to evaluate inflammation of the aorta. Metabolic activity can be measured by an increase in ${ }^{18} \mathrm{~F}$-fluorodeoxy glucose (FDG) uptake as measured by positron emission tomography (PET) or computed tomography (CT). FDG, as a glucose analog that accumulates in high metabolic activity in cells is often used for PET imaging of inflammation (58). Growing evidence show that an increase in ${ }^{18} \mathrm{~F}-\mathrm{FDG}$ uptake is a latent signal in the aorta with active atherosclerotic inflammation $(59,60)$. Many studies have attempted to use ${ }^{18}$ F-FDG to evaluate aortic diseases (61-67). One study used ${ }^{18}$ F-FDG uptake to predict short and midterm prognosis in medically controlled patients with AA dissection by comparing uptake of ${ }^{18} \mathrm{~F}$-FDG in controls and in patients with AAD (Figure 5) (68). This study showed that the ${ }^{18} \mathrm{~F}$-FDG standardized uptake value (SUV) was greater in unfavorable AA dissection groups than in favorable AA dissection groups on 50-minute images (68).
Through the observation of ${ }^{18} \mathrm{~F}-\mathrm{FDG}$ uptake on 100 -minute images, $S \mathrm{SV}_{\text {max }}$ and $\mathrm{SUV}_{\text {mean }}$ of ${ }^{18} \mathrm{~F}$-FDG in the between unfavorable and favorable AA dissection groups were no significant difference and both higher than those in controls at the proximal, distal, and maximum sites (all $\mathrm{P}<0.05$ ). Therefore, use of ${ }^{18} \mathrm{~F}-\mathrm{FDG}$ uptake on 50-minute to stratification patients with AA dissection may be useful for predicting short-term and mid-term prognosis and achieving better management (68). Additionally, many previous studies have shown that FDG in the AA group has higher uptake than that the normal aortic group $(63,65,69)$. Moreover, in AA patients, uptake of FDG is higher in the symptomatic group compared with the asymptomatic group $(67,70)$. Interestingly, sites with a positive ${ }^{18} \mathrm{~F}-\mathrm{FDG}$ uptake have been shown to accumulate a higher amount of adventitial inflammatory cells with a reduction in smooth muscle cells in the media compared with negative ${ }^{18} \mathrm{~F}-\mathrm{FDG}$ samples (71). Therefore, ${ }^{18} \mathrm{~F}$-FDG might be a new pathway to study the mechanical of AA and to predict the risk of rupture. Because of FDG belongs to the glucose, diabetes whether influence FDG uptake due to the state of impaired 
glucose utilization has appeared. Previous studies have suggested that diabetes cannot influence the evaluation of uptake of ${ }^{18} \mathrm{~F}$-FDG in animal trial and human trial. At the moment, the relation of diabetes with AA has also become an attention point. A review suggested that the diabetes is an important risk factor in the coronary and peripheral artery disease, but has a negatively effect in AA due to the hyperinsulinemia can lead to up-regulation fibrinogen, collagen synthesis, plasminogen activator inhibitor- 1 and down regulation fibrinolysis, inflammation and MMP (72-74).

\section{Phagocytosis}

Inflammation is a vital factor in progression of AA. There were histological studies found that lymphocytes and macrophages infiltrate into the aorta occurred during the angiotensin II infusion in apoE $\mathrm{E}^{-/}$mice (75). Macrophages are associated with aneurysm growth and rupture in animal models and patients $(76,77)$. A previous study showed that MRI is a noninvasive method that can be used to assess the morphology of AA (78). Additionally, using MRI to detect macrophages in AA can be used to reflect the degree of inflammation in AA (79). Recently, some studies have also shown that ultrasmall super-paramagnetic iron oxide (USPIO) contrast agents can be used to label atherosclerotic plaques and can indicate the macrophage load when it is used as an imaging agent. Due to the small particle size (10-30 nm), USPIO escapes recognition by the reticuloendothelial system, exists in the blood, and accumulates into the vascular inflammation sites. In these inflammatory sites, USPIO undergoes phagocytosis by tissue-resident macrophages within which it accumulates and is detectable on T2- and T2*-weighted MRI sequences (80-82). In recent research, USPIO contrast agents were used for detecting macrophage infiltration in the pre-clinical formation state of AAA $(83,84)$. The previously study found that compared with mice without a USPIO agent, signal intensity was decreased in mice with a USPIO agent in which many macrophages were observed in remodeled adventitia (Figure 6) (83). These results indicated that with formation of AA, the process of macrophages moving to the aneurysm can be detected by using a USPIO MRI contrast agent. Because of this important discovery, many study groups have attempted to use this particle to study progression of AA $(77,79)$. One other study attempted to show whether uptake of USPIO in the aortic wall was associated with the rate of aneurysm expansion. They divided 27 patients into three groups according to whether uptake of USPIO was in the aortic wall or in thrombus. Finally, they found that the aneurysm expansion rate of focal uptake areas of the aortic wall was three-fold higher than in patients without uptake of USPIO or without specific uptake of USPIO (77). Therefore, USPIO may be able to be applied in the clinic to predict development of AA. However, more human trials are required before use of USPIO in the clinic.

\section{Matrix remodeling targets}

Extracellular matrix degradation is a major factor in formation, dilation and rupture of AA. Additionally, elastin fibers and collagen especially types I and III are vital for retaining the integrity of structure and stability of arteries. Development of AA is associated with degradation of collagen and elastin fibers (85). Cysteine proteases, serine proteases and MMPs produced by inflammatory cells show higher expression in AA than in the normal aorta.

\section{MMP}

MMPs are endopeptidases that can degrade many extracellular proteins (86). Comprehension of regulation of MMP activity is vital for understanding various pathogeneses of AA, and for production of new MMPrelated medicines. All the MMPs have a catalytic center that includes three complexes of the zinc ion in the active place. However, when only MMPs are activated, the zinc ion can be exposed, which is not emergence in inactivated MMPs and MMP proenzymes. Therefore, the zinc ion site may be used to target activation of MMPs (87). Recent data have demonstrated that MMP-1, $-2,-3,-9,-12$, and -13 play roles in progression of AA (85). Their activation can lead to progression of $\mathrm{AA}$ and subsequent rupture or dissection. However, in different types of AA, MMPs significantly increase at various rates. Compared with tricuspid aortic valves (TAVs), MMP-2 levels are increased by $34 \%$ in patients with bicuspid aortic valves (BAVs). However, in TAVs samples, MMP-13 levels are increased by $140 \%$ compared with BAVs (88). Before using MMPs as the target for imaging, the different designs of probes for assessing MMP need to be understood.

Antibodies were used in the earliest attempt to design probes for assessing MMP, and various antibodies have been developed. These antibodies only bind to other epitopes rather than the zinc ion. Therefore, antibodies are not an ideal approach for imaging MMPs (87). Substrates bind to active locations of MMPs and can be cleaned by using enzymes. Moreover, different MMPs have special substrates, which can help to select target MMPs. When 

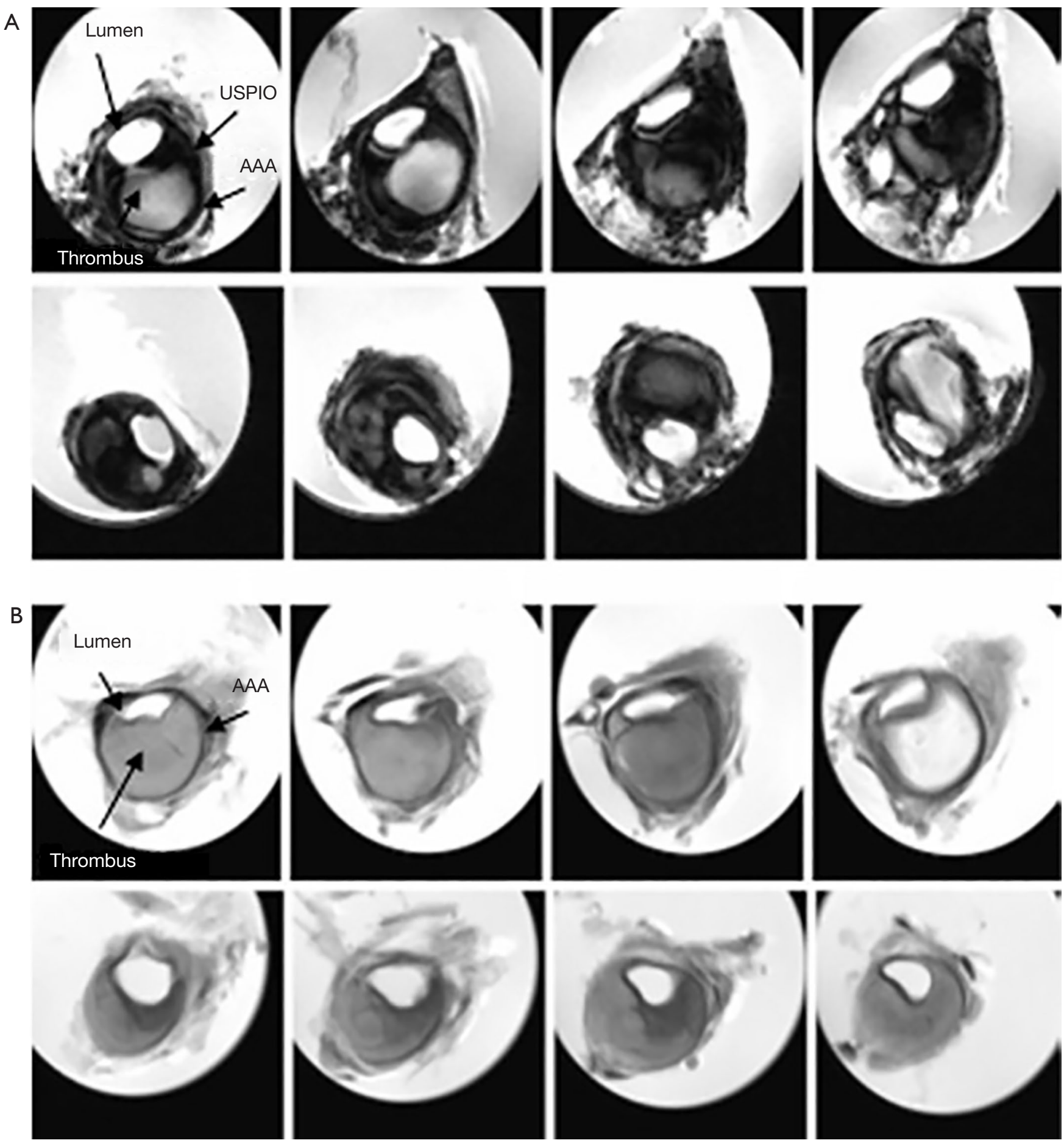

Figure 6 Ex vivo images of AAAs of mice with (A) USPIO administration and (B) without USPIO administration. A macrophage-rich area has decreased signal intensity in USPIO administered mice (83). AAA, abdominal aortic aneurysm; USPIO, ultrasmall super-paramagnetic iron oxide. 
a probe is cleaved, the fluorescent signal is amplified (87). CGS 27023A, a non-specific inhibitor that binds to the active catalytic domain of MMPs, has dominant uptake in the apolipoprotein E-deficient mouse by using microPECT/CT. Although this technique can be used to detect activation of MMPs in aortic disease, it cannot differentiate the type of effect of MMPs in inflammation of the aorta (89). Compared with substrates, inhibitors interact with MMPs in a 1:1 manner and have no signal magnification. Research groups established two nonpeptidic MMP inhibitor-based probes (hydroxamates and barbiturates) to evaluate MMP activity and obtain an ideal outcome (90-92). By using this approach, MMP inhibitors can be used for imaging targets.

Therefore, fluorescence substrates and MMP inhibitors can be used to image inflammatory activity (93-98). RP782 and RP805, special tracers for activated MMPs, are usually used to detect activation of MMPs. Previous studies on cardiovascular disease showed that ${ }^{99 \mathrm{~m}} \mathrm{Tc}-\mathrm{RP} 805$ had significant uptake in the inflammatory area compared with controls by using micro-SPECT. Additionally, ${ }^{99 \mathrm{~m}} \mathrm{Tc}-$ RP805 has a potential value to diagnose changes in MMPs in progression of cardiovascular disease (96-98). Recently, a study reported that a novel MMP inhibitor, RYM, has a faster blood clearance and higher water solubility compared with ${ }^{99 \mathrm{~m}} \mathrm{Tc}-\mathrm{RP} 805$ (93). This finding indicates that ${ }^{99 \mathrm{~m}} \mathrm{Tc}-$ RYM1 can image in the early time, and can improve vessel wall-to-blood contrast. In mice models, micro-PECT/CT imaging showed higher RYM in AAA compared with no dilated aortas (93). Therefore, using MMPs as a target in imaging to predict inflammatory activity in AA has obvious superiority, and this provides a basis for clinical trials.

\section{Matrix proteins}

The aorta has three layers, including the endothelial cells layer, the elastic media layer, and the adventitia. Collagen and elastin form the strength of the aorta and elastic properties of the aorta, respectively (99). Therefore, disruption of these components may change the mechanics of the vessel wall and have a large effect on the pathology of AA. Elastic fibers are highly extensible networks of cross-linked elastin that provide elastic energy storage in tissues and redistribute it during diastole and maintain normal pressure (100). Therefore, elastic degradation can decrease extensibility and increase stiffness. An increased pressure in systole can result in damage of the intima of the aortic wall. Collagen has a large stiffness modulus of approximately 1,200 MPa (approximately 1,000 times greater than elastin) and a low extensibility of approximately
$13 \%$ (100). Therefore, the role of collagen is to reinforce the strength of the wall to avoid rupture of a weak elastic wall. Consequently, destruction of elastin and collagen can lead to apoptosis of vascular smooth muscle cells, which can impair the aortic wall. CAN-35 is a collagen-binding bacterial protein, which can bind to the disorder collagen. It was used as a marker to detect the quantity of collagen in AAA in an animal model (101). A study reported that, using MRI in mice, injection of CAN-35 resulted in higher MR signal compared with mice with no injection mice (102). Therefore, matrix proteins are important targets for evaluating aortic inflammation.

\section{Potential molecular therapeutic targets}

When the diameter of AA exceeds $5.5 \mathrm{~cm}$ in man and $5.0 \mathrm{~cm}$ in women, clinicians always choice artificial vessel replacement or endovascular AA repair (103). However, when the small aneurysm (diameter $>3 \mathrm{~cm}$ ) was detected, current clinicians always choice follow-up CT or ultrasonography in annual 6 to 12 months due to the risk of rupture for aneurysms is low when the diameter of AA smaller than $4 \mathrm{~cm}(104,105)$ and the operative to early stage of AA has no survival advantage $(106,107)$. Thus, the early medicine intervention may become a useful way. The traditional medicine treatment for preventing AA growth is beta-adrenergic receptor blockers (108), and these are useful in treating Marfan syndrome (109). In addition, calcium channel blockers, antiplatelet agents, lipid-lowering drugs, and other antihypertensive drugs are also used to prevent the growth of AA, but there is no obvious impact on aneurysm expansion $(110,111)$. Despite advances in understanding the mechanisms of development of AA, current pharmacological treatment of AA is limited. Research of molecular targets and the area of molecular therapy of AA has become prevalent and there are articles have reported molecular therapy used in the Marfan syndrome and atherosclerotic disease.

\section{Marfan syndrome}

In Marfan syndrome, FBN1 mutations and TGF- $\beta$ results in an imbalance between MMPs and TIMPs, and these can increase proteolysis in the aortic wall and finally cause AA formation $(35,112)$. Much effort has been made to test therapeutic agents aiming the molecular changes, and an angiotensin receptor blocker has been found to inhibit the effect of TGF- $\beta$ in the vascular wall (113-116). Additionally, there is study suggested that the long-term doxycycline, the 
inhibitor of MMP-2 and -9, was more effective than the $\beta$-adrenergic receptor blockers (117).

\section{Atherosclerotic disease}

Atherosclerosis is a chronic progressive disease caused by the inflammatory cellular and molecular changes, such as the macrophage and immune cells accumulation, the inflammation cytokines release. The current treatment point has transferred from tradition medicine (statins) to target inflammation medicine. An article has introduced that Toll-like receptors antagonists, T cells activation inhibitors, TNF and IL-1 receptor inhibitors, kinase inhibitors can be a prospect treatment in atherosclerotic disease (118).

\section{AA}

MMPs are major factors in progression of AA by causing degradation of the extracellular matrix. MMP activity can be suppressed by the tissue inhibitors TIMPs. MMP-2 and MMP-9 are protease that degrade matrix in TAA and AAA (119). Therefore, their role in the extracellular matrix suggests that blocking of MMPs slow progression of aortic disease. Many synthetic MMP inhibitors are known to decrease MMP activity (120), such as doxycycline-based and hydroxamate-based activity. The first synthetic MMP inhibitor that was used in the clinic was BB-94 to reduce MMP activity in cancer (121). However, the feature of poor water solubility has limited the effectiveness of BB-94 when provided orally. Doxycycline is associated with positive results in clinical trials involving small AAA. Doxycycline reduces plasma MMP-9 levels and significantly lowers aneurysmal growth rates in patients (122-124). Many studies have reported that in animal models, systemic MMP inhibitors can reduce the onset of aneurysms $(125,126)$. However, systemic delivery may limit normal MMP activity, which is not the original aim of using MMP inhibitors.

Recently, many studies have investigated how to reduce the side effects of MMP inhibitors and increase accumulated concentrations. These studies showed that MMP inhibitors that were loaded with nanoparticles were localized in inflammation or pathological regions (127-131). However, drug-loaded nanoparticles are usually toxic and can cause adverse effects because of exposed in the circular to deliver. Additionally, rapid clearance of nanoparticles from the plasma limits use of nanoparticles in humans $(132,133)$. Therefore, many alternative drugs for delivery to cells are being studied worldwide, especially for tumors using intrinsic functional cells. Intrinsic functional cells include macrophages, mesenchymal stem cells, natural killer cells, and mature erythrocytes (134-137). The pathological features of AA are degradation of the extracellular matrix and a decrease in vascular smooth muscle cells, associated with inflammatory cell infiltration. Additionally, macrophages have a major function in inflammatory progression. Therefore, macrophages may have the chance to become drug carriers (138). A previous study attempted to use the macrophage membrane to deliver nanoparticles (emtansine liposome). This study showed that emtansine liposomes coated with macrophage membranes had long-term stability in plasma and resulted in a higher accumulation of concentrations compared with emtansine liposomes alone. Many research groups have also attempted to use membranes to treat AA (131). We hypothesize that using macrophages to coat nanoparticles with MMP inhibitors is useful for treating AA. However, long-term in vivo trials are required before using this technique in the clinic.

\section{Conclusions}

The incidence of AA has increased in the last 50 years. Techniques of diagnosis of AA need to progress to reduce the rate of morbidity and mortality. Understanding the mechanisms of development of AA could lead to discovering newer potential methods of substituting the traditional diagnosis and therapeutic approaches. In the future, molecular targets for AA may become an attractive aspect and be used in the clinic. However, target imaging for diagnosing AA requires more pre-clinical trials. Additionally, using target drugs to the diseased site is difficult because of complex blood flow and limited biofabrication technology. Nanoparticles may be an effective vehicle for delivering therapeutic agents to the target site. These particles can lead to target drug concentrations reaching a high level in specified sites and a decrease in distribution in other sites. Therefore, molecular targets may be good candidates for a future study direction in the management of AA. The new prospect treatment may available prevent the small $\mathrm{AA}$ dilation and reduce the rate of $\mathrm{AA}$ growth for more and elderly patients. Besides that, the intervention could be suggested in the early stage based on the molecular target.

\section{Acknowledgements}

Funding: The authors acknowledge fundings from the National Science Foundation of China (Grant 
No. 81301312, 481570422, 81500194, 81570422), "Chen Guang” project supported by Shanghai Municipal Education Commission and Shanghai Education Development Foundation (Grant No. 14CG06), Shanghai Pujiang Program (17PJ1401500), Youth Foundation of Zhongshan Hospital (Grant No. 2015ZSQN48) and Talent Training Program Foundation for the Excellent Youth Supported by Zhongshan Hospital (Grant No. 2015ZSYXQN12).

\section{Footnote}

Conflicts of Interest: The authors have no conflicts of interest to declare.

\section{References}

1. Clouse WD, Hallett JW Jr, Schaff HV, et al. Improved prognosis of thoracic aortic aneurysms: a population-based study. JAMA 1998;280:1926-9.

2. Ramanath VS, Oh JK, Sundt TM 3rd, et al. Acute aortic syndromes and thoracic aortic aneurysm. Mayo Clin Proc 2009;84:465-81.

3. Kuzmik GA, Sang AX, Elefteriades JA. Natural history of thoracic aortic aneurysms. J Vasc Surg 2012;56:565-71.

4. Drott C, Arfvidsson B, Ortenwall P, et al. Age-standardized incidence of ruptured aortic aneurysm in a defined Swedish population between 1952 and 1988: mortality rate and operative results. Br J Surg 1992;79:175-9.

5. Svensjö S, Bengtsson H, Bergqvist D. Thoracic and thoracoabdominal aortic aneurysm and dissection: an investigation based on autopsy. Br J Surg 1996;83:68-71.

6. Clouse WD, Hallett JW Jr, Schaff HV, et al. Acute aortic dissection: population-based incidence compared with degenerative aortic aneurysm rupture. Mayo Clin Proc 2004;79:176-80.

7. Blankensteijn JD, Lindenburg FP, Van der Graaf Y, et al. Influence of study design on reported mortality and morbidity rates after abdominal aortic aneurysm repair. $\mathrm{Br}$ J Surg 1998;85:1624-30.

8. Nordon IM, Hinchliffe RJ, Loftus IM, et al. Pathophysiology and epidemiology of abdominal aortic aneurysms. Nat Rev Cardiol 2011;8:92-102.

9. El-Hamamsy I, Yacoub MH. Cellular and molecular mechanisms of thoracic aortic aneurysms. Nat Rev Cardiol 2009;6:771-86.

10. Kuivaniemi H, Ryer EJ, Elmore JR, et al. Understanding the pathogenesis of abdominal aortic aneurysms. Expert Rev Cardiovasc Ther 2015;13:975-87.
11. Gillis E, Van Laer L, Loeys BL. Genetics of thoracic aortic aneurysm: at the crossroad of transforming growth factor-beta signaling and vascular smooth muscle cell contractility. Circ Res 2013;113:327-40.

12. Bee KJ, Wilkes DC, Devereux RB, et al. TGFbetaRIIb mutations trigger aortic aneurysm pathogenesis by altering transforming growth factor beta2 signal transduction. Circ Cardiovasc Genet 2012;5:621-9.

13. Liapis CD, Paraskevas KI. The pivotal role of matrix metalloproteinases in the development of human abdominal aortic aneurysms. Vasc Med 2003;8:267-71.

14. Thompson RW, Geraghty PJ, Lee JK. Abdominal aortic aneurysms: basic mechanisms and clinical implications. Curr Probl Surg 2002;39:110-230 .

15. Mizuguchi T, Collod-Beroud G, Akiyama T, et al. Heterozygous TGFBR2 mutations in Marfan syndrome. Nat Genet 2004;36:855-60.

16. Selvamurugan N, Kwok S, Alliston T, et al. Transforming growth factor-beta 1 regulation of collagenase- 3 expression in osteoblastic cells by cross-talk between the Smad and MAPK signaling pathways and their components, Smad2 and Runx2. J Biol Chem 2004;279:19327-34.

17. Loeys BL, Chen J, Neptune ER, et al. A syndrome of altered cardiovascular, craniofacial, neurocognitive and skeletal development caused by mutations in TGFBR1 or TGFBR2. Nat Genet 2005;37:275-81.

18. Palombo D, Maione M, Cifiello BI, et al. Matrix metalloproteinases. Their role in degenerative chronic diseases of abdominal aorta. J Cardiovasc Surg (Torino) 1999;40:257-60.

19. Thompson RW, Holmes DR, Mertens RA, et al. Production and localization of 92-kilodalton gelatinase in abdominal aortic aneurysms. An elastolytic metalloproteinase expressed by aneurysm-infiltrating macrophages. J Clin Invest 1995;96:318-26.

20. Tamarina NA, McMillan WD, Shively VP, et al. Expression of matrix metalloproteinases and their inhibitors in aneurysms and normal aorta. Surgery 1997;122:264-71; discussion 271-2.

21. Rabkin SW. Differential expression of MMP-2, MMP9 and TIMP proteins in thoracic aortic aneurysm comparison with and without bicuspid aortic valve: a metaanalysis. Vasa 2014;43:433-42.

22. Nagasawa A, Yoshimura K, Suzuki R, et al. Important role of the angiotensin II pathway in producing matrix metalloproteinase-9 in human thoracic aortic aneurysms. J Surg Res 2013;183:472-7.

23. Visse R, Nagase H. Matrix metalloproteinases and tissue 
inhibitors of metalloproteinases: structure, function, and biochemistry. Circ Res 2003;92:827-39.

24. Coady MA, Rizzo JA, Hammond GL, et al. What is the appropriate size criterion for resection of thoracic aortic aneurysms? J Thorac Cardiovasc Surg 1997;113:476-91; discussion 89-91.

25. Davies RR, Kaple RK, Mandapati D, et al. Natural history of ascending aortic aneurysms in the setting of an unreplaced bicuspid aortic valve. Ann Thorac Surg 2007;83:1338-44.

26. Cosford PA, Leng GC. Screening for abdominal aortic aneurysm. Cochrane Database Syst Rev 2007:CD002945.

27. Nevitt MP, Ballard DJ, Hallett JW Jr. Prognosis of abdominal aortic aneurysms. A population-based study. N Engl J Med 1989;321:1009-14.

28. Collin J, Araujo L, Walton J. How fast do very small abdominal aortic aneurysms grow? Eur J Vasc Surg 1989;3:15-7.

29. Bernstein EF, Chan EL. Abdominal aortic aneurysm in high-risk patients. Outcome of selective management based on size and expansion rate. Ann Surg 1984;200:255-63.

30. Delin A, Ohlsen H, Swedenborg J. Growth rate of abdominal aortic aneurysms as measured by computed tomography. Br J Surg 1985;72:530-2.

31. Guirguis EM, Barber GG. The natural history of abdominal aortic aneurysms. Am J Surg 1991;162:481-3.

32. Cronenwett JL, Murphy TF, Zelenock GB, et al. Actuarial analysis of variables associated with rupture of small abdominal aortic aneurysms. Surgery 1985;98:472-83.

33. Akai A, Watanabe Y, Hoshina K, et al. Family history of aortic aneurysm is an independent risk factor for more rapid growth of small abdominal aortic aneurysms in Japan. J Vasc Surg 2015;61:287-90.

34. Hannuksela M, Stattin EL, Johansson B, et al. Screening for Familial Thoracic Aortic Aneurysms with Aortic Imaging Does Not Detect All Potential Carriers of the Disease. Aorta (Stamford) 2015;3:1-8. .

35. Ramachandra CJ, Mehta A, Guo KW, et al. Molecular pathogenesis of Marfan syndrome. Int J Cardiol 2015;187:585-91.

36. Linné A, Forsberg J, Lindström D, et al. Age at detection of abdominal aortic aneurysms in siblings of patients with abdominal aortic aneurysms. J Vasc Surg 2016;63:883-7.

37. Regalado E, Medrek S, Tran-Fadulu V, et al. Autosomal dominant inheritance of a predisposition to thoracic aortic aneurysms and dissections and intracranial saccular aneurysms. Am J Med Genet A 2011;155A:2125-30.

38. Robertson EN, van der Linde D, Sherrah AG, et al.
Familial non-syndromal thoracic aortic aneurysms and dissections - Incidence and family screening outcomes. Int J Cardiol 2016;220:43-51.

39. Koullias G, Modak R, Tranquilli M, et al. Mechanical deterioration underlies malignant behavior of aneurysmal human ascending aorta. J Thorac Cardiovasc Surg 2005;130:677-83.

40. Raghavan ML, Vorp DA, Federle MP, et al. Wall stress distribution on three-dimensionally reconstructed models of human abdominal aortic aneurysm. J Vasc Surg 2000;31:760-9.

41. Poullis MP, Warwick R, Oo A, et al. Ascending aortic curvature as an independent risk factor for type A dissection, and ascending aortic aneurysm formation: a mathematical model. Eur J Cardiothorac Surg 2008;33:995-1001.

42. Leung JH, Wright AR, Cheshire N, et al. Fluid structure interaction of patient specific abdominal aortic aneurysms: a comparison with solid stress models. Biomed Eng Online 2006;5:33.

43. Sans M, Moragas A. Mathematical morphologic analysis of the aortic medial structure. Biomechanical implications. Anal Quant Cytol Histol 1993;15:93-100.

44. Baxter BT, Davis VA, Minion DJ, et al. Abdominal aortic aneurysms are associated with altered matrix proteins of the nonaneurysmal aortic segments. J Vasc Surg 1994;19:797-802; discussion 803.

45. Brophy CM, Reilly JM, Smith GJ, et al. The role of inflammation in nonspecific abdominal aortic aneurysm disease. Ann Vasc Surg 1991;5:229-33.

46. Lindholt JS, Ashton HA, Heickendorff L, et al. Serum elastin peptides in the preoperative evaluation of abdominal aortic aneurysms. Eur J Vasc Endovasc Surg 2001;22:546-50.

47. Petersen E, Gineitis A, Wagberg F, et al. Serum levels of elastin-derived peptides in patients with ruptured and asymptomatic abdominal aortic aneurysms. Eur J Vasc Endovasc Surg 2001;22:48-52.

48. Lindholt JS, Heickendorff L, Vammen S, et al. Five-year results of elastin and collagen markers as predictive tools in the management of small abdominal aortic aneurysms. Eur J Vasc Endovasc Surg 2001;21:235-40.

49. Norman P, Spencer CA, Lawrence-Brown MM, et al. C-reactive protein levels and the expansion of screendetected abdominal aortic aneurysms in men. Circulation 2004;110:862-6.

50. Juvonen J, Surcel HM, Satta J, et al. Elevated circulating levels of inflammatory cytokines in patients with 
abdominal aortic aneurysm. Arterioscler Thromb Vasc Biol 1997; 17:2843-7.

51. Jones KG, Brull DJ, Brown LC, et al. Interleukin-6 (IL$6)$ and the prognosis of abdominal aortic aneurysms. Circulation 2001;103:2260-5.

52. Takagi H, Manabe H, Kawai N, et al. Circulating matrix metalloproteinase- 9 concentrations and abdominal aortic aneurysm presence: a meta-analysis. Interact Cardiovasc Thorac Surg 2009;9:437-40.

53. Wilson WR, Anderton M, Choke EC, et al. Elevated plasma MMP1 and MMP9 are associated with abdominal aortic aneurysm rupture. Eur J Vasc Endovasc Surg 2008;35:580-4.

54. Rohde LE, Arroyo LH, Rifai N, et al. Plasma concentrations of interleukin- 6 and abdominal aortic diameter among subjects without aortic dilatation. Arterioscler Thromb Vasc Biol 1999;19:1695-9.

55. Hellenthal FA, Buurman WA, Wodzig WK, et al. Biomarkers of abdominal aortic aneurysm progression. Part 2: inflammation. Nat Rev Cardiol 2009;6:543-52.

56. He R, Guo DC, Estrera AL, et al. Characterization of the inflammatory and apoptotic cells in the aortas of patients with ascending thoracic aortic aneurysms and dissections. J Thorac Cardiovasc Surg 2006;131:671-8.

57. Ghorpade A, Baxter BT. Biochemistry and molecular regulation of matrix macromolecules in abdominal aortic aneurysms. Ann N Y Acad Sci 1996;800:138-50.

58. Zhuang H, Alavi A. 18-fluorodeoxyglucose positron emission tomographic imaging in the detection and monitoring of infection and inflammation. Semin Nucl Med 2002;32:47-59.

59. Rudd JH, Warburton EA, Fryer TD, et al. Imaging atherosclerotic plaque inflammation with $[18 \mathrm{~F}]-$ fluorodeoxyglucose positron emission tomography. Circulation 2002;105:2708-11.

60. Dunphy MP, Freiman A, Larson SM, et al. Association of vascular $18 \mathrm{~F}-\mathrm{FDG}$ uptake with vascular calcification. J Nucl Med 2005;46:1278-84.

61. Huang Y, Teng Z, Elkhawad M, et al. High Structural Stress and Presence of Intraluminal Thrombus Predict Abdominal Aortic Aneurysm 18F-FDG Uptake: Insights From Biomechanics. Circ Cardiovasc Imaging 2016;9. pii: e004656.

62. English SJ, Piert MR, Diaz JA, et al. Increased 18F-FDG uptake is predictive of rupture in a novel rat abdominal aortic aneurysm rupture model. Ann Surg 2015;261:395-404.

63. Kotze CW, Menezes LJ, Endozo R, et al. Increased metabolic activity in abdominal aortic aneurysm detected by $18 \mathrm{~F}$-fluorodeoxyglucose (18F-FDG) positron emission tomography/computed tomography (PET/CT). Eur J Vasc Endovasc Surg 2009;38:93-9.

64. Xu XY, Borghi A, Nchimi A, et al. High levels of 18F-FDG uptake in aortic aneurysm wall are associated with high wall stress. Eur J Vasc Endovasc Surg 2010;39:295-301.

65. Truijers M, Kurvers HA, Bredie SJ, et al. In vivo imaging of abdominal aortic aneurysms: increased FDG uptake suggests inflammation in the aneurysm wall. J Endovasc Ther 2008; 15:462-7.

66. Ben-Haim S, Kupzov E, Tamir A, et al. Evaluation of 18F-FDG uptake and arterial wall calcifications using 18F-FDG PET/CT. J Nucl Med 2004;45:1816-21.

67. Reeps C, Essler M, Pelisek J, et al. Increased $18 \mathrm{~F}$-fluorodeoxyglucose uptake in abdominal aortic aneurysms in positron emission/computed tomography is associated with inflammation, aortic wall instability, and acute symptoms. J Vasc Surg 2008;48:417-23; discussion 24.

68. Kato K, Nishio A, Kato N, et al. Uptake of 18F-FDG in acute aortic dissection: a determinant of unfavorable outcome. J Nucl Med 2010;51:674-81.

69. Sakalihasan N, Van Damme H, Gomez P, et al. Positron emission tomography (PET) evaluation of abdominal aortic aneurysm (AAA). Eur J Vasc Endovasc Surg 2002;23:431-6.

70. Tsuruda T, Nagamachi S, Nishimura M, et al. Multiple 18F-Fluorodeoxyglucose Positron Emission Tomography Scans Showing Progression of Abdominal Aortic Aneurysm: A Case Report. Medicine (Baltimore) 2016;95:e3650.

71. Courtois A, Nusgens BV, Hustinx R, et al. 18F-FDG uptake assessed by PET/CT in abdominal aortic aneurysms is associated with cellular and molecular alterations prefacing wall deterioration and rupture. J Nucl Med 2013;54:1740-7.

72. Takagi H, Takuya Umemoto for the AG. Association of diabetes mellitus with presence, expansion, and rupture of abdominal aortic aneurysm: "Curiouser and curiouser!" cried ALICE. Semin Vasc Surg 2016;29:18-26.

73. Silvola JM, Saraste A, Laitinen I, et al. Effects of age, diet, and type 2 diabetes on the development and FDG uptake of atherosclerotic plaques. JACC Cardiovasc Imaging 2011;4:1294-301.

74. Schinkel AF, Bax JJ, Valkema R, et al. Effect of diabetes mellitus on myocardial 18F-FDG SPECT using acipimox for the assessment of myocardial viability. J Nucl Med 2003;44:877-83.

75. Saraff K, Babamusta F, Cassis LA, et al. Aortic dissection 
precedes formation of aneurysms and atherosclerosis in angiotensin II-infused, apolipoprotein E-deficient mice. Arterioscler Thromb Vasc Biol 2003;23:1621-6.

76. Nahrendorf M, Keliher E, Marinelli B, et al. Detection of macrophages in aortic aneurysms by nanoparticle positron emission tomography-computed tomography. Arterioscler Thromb Vasc Biol 2011;31:750-7.

77. Richards JM, Semple SI, MacGillivray TJ, et al. Abdominal aortic aneurysm growth predicted by uptake of ultrasmall superparamagnetic particles of iron oxide: a pilot study. Circ Cardiovasc Imaging 2011;4:274-81.

78. Turner GH, Olzinski AR, Bernard RE, et al. In vivo serial assessment of aortic aneurysm formation in apolipoprotein E-deficient mice via MRI. Circ Cardiovasc Imaging 2008;1:220-6.

79. Truijers M, Fütterer JJ, Takahashi S, et al. In vivo imaging of the aneurysm wall with MRI and a macrophage-specific contrast agent. AJR Am J Roentgenol 2009;193:W437-41.

80. Kooi ME, Cappendijk VC, Cleutjens KB, et al. Accumulation of ultrasmall superparamagnetic particles of iron oxide in human atherosclerotic plaques can be detected by in vivo magnetic resonance imaging. Circulation 2003;107:2453-8.

81. Trivedi RA, Mallawarachi C, U-King-Im JM, et al. Identifying inflamed carotid plaques using in vivo USPIOenhanced MR imaging to label plaque macrophages. Arterioscler Thromb Vasc Biol 2006;26:1601-6.

82. Tang TY, Howarth SP, Miller SR, et al. The ATHEROMA (Atorvastatin Therapy: Effects on Reduction of Macrophage Activity) Study. Evaluation using ultrasmall superparamagnetic iron oxide-enhanced magnetic resonance imaging in carotid disease. J Am Coll Cardiol 2009;53:2039-50.

83. Turner GH, Olzinski AR, Bernard RE, et al. Assessment of macrophage infiltration in a murine model of abdominal aortic aneurysm. J Magn Reson Imaging 2009;30:455-60.

84. Sadat U, Taviani V, Patterson AJ, et al. Ultrasmall superparamagnetic iron oxide-enhanced magnetic resonance imaging of abdominal aortic aneurysms--a feasibility study. Eur J Vasc Endovasc Surg 2011;41:167-74.

85. Shimizu K, Mitchell RN, Libby P. Inflammation and cellular immune responses in abdominal aortic aneurysms. Arterioscler Thromb Vasc Biol 2006;26:987-94.

86. Hadler-Olsen E, Fadnes B, Sylte I, et al. Regulation of matrix metalloproteinase activity in health and disease. FEBS J 2011;278:28-45.

87. Schäfers M, Schober O, Hermann S. Matrixmetalloproteinases as imaging targets for inflammatory activity in atherosclerotic plaques. J Nucl Med 2010;51:663-6.

88. Ikonomidis JS, Jones JA, Barbour JR, et al. Expression of matrix metalloproteinases and endogenous inhibitors within ascending aortic aneurysms of patients with bicuspid or tricuspid aortic valves. J Thorac Cardiovasc Surg 2007;133:1028-36.

89. Schäfers M, Riemann B, Kopka K, et al. Scintigraphic imaging of matrix metalloproteinase activity in the arterial wall in vivo. Circulation 2004;109:2554-9.

90. Breyholz HJ, Wagner S, Levkau B, et al. A $18 \mathrm{~F}$-radiolabeled analogue of CGS $27023 \mathrm{~A}$ as a potential agent for assessment of matrix-metalloproteinase activity in vivo. Q J Nucl Med Mol Imaging 2007;51:24-32.

91. Wagner S, Breyholz HJ, Law MP, et al. Novel fluorinated derivatives of the broad-spectrum MMP inhibitors N-hydroxy-2(R)-[[(4-methoxyphenyl)sulfonyl](benzyl)and (3-picolyl)-amino]-3-methyl-butanamide as potential tools for the molecular imaging of activated MMPs with PET. J Med Chem 2007;50:5752-64.

92. Faust A, Waschkau B, Waldeck J, et al. Synthesis and evaluation of a novel fluorescent photoprobe for imaging matrix metalloproteinases. Bioconjug Chem 2008;19:1001-8.

93. Toczek J, Ye Y, Gona K, et al. Preclinical Evaluation of RYM1, a Matrix Metalloproteinase-Targeted Tracer for Imaging Aneurysm. J Nucl Med 2017;58:1318-23.

94. Sheth RA, Maricevich M, Mahmood U. In vivo optical molecular imaging of matrix metalloproteinase activity in abdominal aortic aneurysms correlates with treatment effects on growth rate. Atherosclerosis 2010;212:181-7.

95. Fujimoto S, Hartung D, Ohshima S, et al. Molecular imaging of matrix metalloproteinase in atherosclerotic lesions: resolution with dietary modification and statin therapy. J Am Coll Cardiol 2008;52:1847-57.

96. Su H, Spinale FG, Dobrucki LW, et al. Noninvasive targeted imaging of matrix metalloproteinase activation in a murine model of postinfarction remodeling. Circulation 2005;112:3157-67.

97. Zhang J, Nie L, Razavian M, et al. Molecular imaging of activated matrix metalloproteinases in vascular remodeling. Circulation 2008;118:1953-60.

98. Razavian M, Zhang J, Nie L, et al. Molecular imaging of matrix metalloproteinase activation to predict murine aneurysm expansion in vivo. J Nucl Med 2010;51:1107-15.

99. Gasser TC, Ogden RW, Holzapfel GA. Hyperelastic modelling of arterial layers with distributed collagen fibre orientations. J R Soc Interface 2006;3:15-35.

100. Gosline J, Lillie M, Carrington E, et al. Elastic proteins: 
biological roles and mechanical properties. Philos Trans $\mathrm{R}$ Soc Lond B Biol Sci 2002;357:121-32.

101. Sanders HM, Iafisco M, Pouget EM, et al. The binding of CNA35 contrast agents to collagen fibrils. Chem Commun (Camb) 2011;47:1503-5.

102.Klink A, Heynens J, Herranz B, et al. In vivo characterization of a new abdominal aortic aneurysm mouse model with conventional and molecular magnetic resonance imaging. J Am Coll Cardiol 2011;58:2522-30.

103. Lederle FA, Johnson GR, Wilson SE, et al. Rupture rate of large abdominal aortic aneurysms in patients refusing or unfit for elective repair. JAMA 2002;287:2968-72.

104. Brown LC, Powell JT. Risk factors for aneurysm rupture in patients kept under ultrasound surveillance. UK Small Aneurysm Trial Participants. Ann Surg 1999;230:289-96; discussion 96-7.

105. Nicholls SC, Gardner JB, Meissner MH, et al. Rupture in small abdominal aortic aneurysms. J Vasc Surg 1998;28:884-8.

106. Cao P, De Rango P, Verzini F, et al. Comparison of surveillance versus aortic endografting for small aneurysm repair (CAESAR): results from a randomised trial. Eur J Vasc Endovasc Surg 2011;41:13-25.

107. The UK Small Aneurysm Trial Participants. Mortality results for randomised controlled trial of early elective surgery or ultrasonographic surveillance for small abdominal aortic aneurysms. Lancet 1998;352:1649-55.

108. Matt P, Habashi J, Carrel T, et al. Recent advances in understanding Marfan syndrome: should we now treat surgical patients with losartan? J Thorac Cardiovasc Surg 2008;135:389-94.

109. Silverman DI, Burton KJ, Gray J, et al. Life expectancy in the Marfan syndrome. Am J Cardiol 1995;75:157-60.

110.Lindholt JS, Henneberg EW, Juul S, et al. Impaired results of a randomised double blinded clinical trial of propranolol versus placebo on the expansion rate of small abdominal aortic aneurysms. Int Angiol 1999;18:52-7.

111.Propanolol Aneurysm Trial Investigators. Propranolol for small abdominal aortic aneurysms: results of a randomized trial. J Vasc Surg 2002;35:72-9.

112. Neptune ER, Frischmeyer PA, Arking DE, et al. Dysregulation of TGF-beta activation contributes to pathogenesis in Marfan syndrome. Nat Genet 2003;33:407-11.

113.Matt P, Schoenhoff F, Habashi J, et al. Circulating transforming growth factor-beta in Marfan syndrome. Circulation 2009;120:526-32.

114. Habashi JP, Judge DP, Holm TM, et al. Losartan, an AT1 antagonist, prevents aortic aneurysm in a mouse model of Marfan syndrome. Science 2006;312:117-21.

115. Pyeritz RE, Loeys B. The 8th international research symposium on the Marfan syndrome and related conditions. Am J Med Genet A 2012;158A:42-9.

116. Lindsay ME, Dietz HC. Lessons on the pathogenesis of aneurysm from heritable conditions. Nature 2011;473:308-16.

117. Chung AW, Yang HH, Radomski MW, et al. Long-term doxycycline is more effective than atenolol to prevent thoracic aortic aneurysm in marfan syndrome through the inhibition of matrix metalloproteinase-2 and -9. Circ Res 2008;102:e73-85.

118. Gómez-Guerrero C, Mallavia B, Egido J. Targeting inflammation in cardiovascular diseases. still a neglected field? Cardiovasc Ther 2012;30:e189-97.

119.Longo GM, Xiong W, Greiner TC, et al. Matrix metalloproteinases 2 and 9 work in concert to produce aortic aneurysms. J Clin Invest 2002;110:625-32.

120. Kadoglou NP, Liapis CD. Matrix metalloproteinases: contribution to pathogenesis, diagnosis, surveillance and treatment of abdominal aortic aneurysms. Curr Med Res Opin 2004;20:419-32.

121.Erba E, Ronzoni S, Bassano L, et al. The metalloproteinase inhibitor batimastat (BB-94) causes cell cycle phase perturbations in ovarian cancer cells. Ann Oncol 1999;10:589-91.

122.Lindeman JH, Abdul-Hussien H, van Bockel JH, et al. Clinical trial of doxycycline for matrix metalloproteinase-9 inhibition in patients with an abdominal aneurysm: doxycycline selectively depletes aortic wall neutrophils and cytotoxic T cells. Circulation 2009;119:2209-16.

123. Baxter BT, Pearce WH, Waltke EA, et al. Prolonged administration of doxycycline in patients with small asymptomatic abdominal aortic aneurysms: report of a prospective (Phase II) multicenter study. J Vasc Surg 2002;36:1-12.

124.Mosorin M, Juvonen J, Biancari F, et al. Use of doxycycline to decrease the growth rate of abdominal aortic aneurysms: a randomized, double-blind, placebo-controlled pilot study. J Vasc Surg 2001;34:606-10.

125.Abbruzzese TA, Guzman RJ, Martin RL, et al. Matrix metalloproteinase inhibition limits arterial enlargements in a rodent arteriovenous fistula model. Surgery 1998;124:328-34; discussion 34-5.

126. Moore G, Liao S, Curci JA, et al. Suppression of experimental abdominal aortic aneurysms by systemic treatment with a hydroxamate-based matrix metalloproteinase inhibitor (RS 132908). J Vasc Surg 
1999;29:522-32.

127. Sivaraman B, Ramamurthi A. Multifunctional nanoparticles for doxycycline delivery towards localized elastic matrix stabilization and regenerative repair. Acta Biomater 2013;9:6511-25.

128.Meng H, Xing G, Blanco E, et al. Gadolinium metallofullerenol nanoparticles inhibit cancer metastasis through matrix metalloproteinase inhibition: imprisoning instead of poisoning cancer cells. Nanomedicine 2012;8:136-46.

129. Ruoslahti E, Bhatia SN, Sailor MJ. Targeting of drugs and nanoparticles to tumors. J Cell Biol 2010;188:759-68.

130.Du C, Deng D, Shan L, et al. A pH-sensitive doxorubicin prodrug based on folate-conjugated BSA for tumortargeted drug delivery. Biomaterials 2013;34:3087-97.

131. Nosoudi N, Nahar-Gohad P, Sinha A, et al. Prevention of abdominal aortic aneurysm progression by targeted inhibition of matrix metalloproteinase activity with batimastat-loaded nanoparticles. Circ Res 2015;117:e80-9. 132. Petros RA, DeSimone JM. Strategies in the design of

Cite this article as: $\mathrm{Hu} \mathrm{C}$, Zhu K, Li J, Wang C, Lai L. Molecular targets in aortic aneurysm for establishing novel management paradigms. J Thorac Dis 2017;9(11):4708-4722. doi: $10.21037 /$ jtd.2017.10.63 nanoparticles for therapeutic applications. Nat Rev Drug Discov 2010;9:615-27.

133. Suk JS, Xu Q, Kim N, et al. PEGylation as a strategy for improving nanoparticle-based drug and gene delivery. Adv Drug Deliv Rev 2016;99:28-51.

134. Gao Z, Zhang L, Hu J, et al. Mesenchymal stem cells: a potential targeted-delivery vehicle for anti-cancer drug, loaded nanoparticles. Nanomedicine 2013;9:174-84.

135. Wei X, Yang X, Han ZP, et al. Mesenchymal stem cells: a new trend for cell therapy. Acta Pharmacol Sin 2013;34:747-54.

136. Cao H, Dan Z, He X, et al. Liposomes Coated with Isolated Macrophage Membrane Can Target Lung Metastasis of Breast Cancer. ACS Nano 2016;10:7738-48.

137. García-Castro J, Martínez-Palacio J, Lillo R, et al. Tumor cells as cellular vehicles to deliver gene therapies to metastatic tumors. Cancer Gene Ther 2005;12:341-9.

138. Raffort J, Lareyre F, Clement M, et al. Monocytes and macrophages in abdominal aortic aneurysm. Nat Rev Cardiol 2017;14:457-71. 